\title{
Educação em Direitos Humanos e o Mal-Estar em Educar na Pós-Modernidade: Uma Discussão Interdisciplinar a Partir da Psicanálise
}

\author{
Cleber Lizardo de Assis \\ Psicólogo e educador. Mestre em Psicologia/Processos \\ Psicossociais-PUC Minas. Docente do curso de Psicologia \\ da Unesc-RO. Doutorando em Psicologia na Universidad \\ del Salvador-AR. Ex-integrante do Fórum Mineiro de \\ Direitos Humanos e do Comitê Mineiro de Educação em \\ Direitos Humanos. kebelassis@yahoo.com.br
}

\begin{abstract}
Resumo
Objetiva-se operar uma reflexão sobre 0 ato de educar em direitos humanos na Pós-Modernidade, considerando as demandas desse contexto de fragilização do laço social; adota-se como método a análise teórico-crítica de conceitos e autores que problematizam a condição psicossocial contemporânea como da ordem do mal-estar; Contextualiza-se historicamente a noção de direitos humanos no cenário internacional e brasileiro, em especial na perspectiva da educação em direitos humanos preconizado pela Secretaria Especial de Direitos Humanos e o Plano Nacional de Educação em Direitos Humanos; discute-se a situação do ethos contemporâneo denominado de "pós-moderno", quando se destaca suas diversas características e sua relação com o que se denomina de fragilização do laço social que impõe ao ato educativo um mal-estar; como resultado, a partir de autores e conceitos da sociologia, psicossociologia e psicanálise, postula-se como existente esse mal-estar inerente no processo educativo e, em especial, na ótica dos direitos humanos; discute-se ainda a necessidade de articulação de uma educação que organize espaços formais e informais, academia e sociedade civil, a partir dos postulados da Conferência de Jomtien, para apontar o caso da Família contemporânea como exemplo em que o Direito, a Psicologia e a Educação podem atuar de forma interdisciplinar; conclui-se, defendendo uma articulação entre as disciplinas Psicologia, Direito e Educação a um processo educativo promotor de laço social digno, saudável e cidadão.
\end{abstract}

Palavras-chave: Educação em Direitos Humanos. Pós-Modernidade. Psicanálise. 


\title{
Human Rights Education and Malaise in Education in Post-Modernity: An interdisciplinary discussion from Psychoanalysis
}

\begin{abstract}
We aim to objetive a reflection on the act of educating in human rights in post-modernity, considering the demands of the context of weakening social ties; adopted as the method of theoretical analysis and critical concepts and authors that question the contemporary psychosocial condition as the order of malaise; historically contextualizes up the notion of human rights in the international arena and Brazil, in particular, from the perspective of human rights education recommended by the special Secretaria for Human Rights and National Plan for Human Rights Education; discusses the situation of the contemporary ethos called "postmodern", where we highlight its different characteristics and their relation to what is called the weakening of social ties to the educational act that imposes a malaise; completion, the from authors and concepts of sociology, social psychology and psychoanalysis posits itself as existing this malaise inherent in the educational process and in particular in the perspective of human rights; discusses the need for articulation of an education that combines formal and informal spaces, academia and civil society from the postulates of the Jomtien Conference, point to the case as Family contemporary example of the Law, the Psychology and Education that can act interdisciplinary; as a result, advocates a articulation between the disciplines Psychology, Law and Education to sponsor an educational process of social ties dignified, healthy and citizen.
\end{abstract}

Keywords: Human Rights Education. Post-Modernity. Psychoanálysis.

\section{Sumário}

1 Introdução. 2 Mal-estar no laço social e na educação. 3 Desafios à psicologia e ao direito: uma educação promotora de laço social e de humanização. 40 caso da família atual como exemplo de educação em direitos humanos. 5 Considerações finais. 6 Referências. 


\section{INTRODUÇÃO}

Os direitos humanos têm sido discutidos, afirmados ou negados ao longo dos tempos. Embora a concepção de que toda pessoa humana possui direitos básicos e inalienáveis seja bem antiga, alguns representam os marcos que foram cunhando a expressão tal como a possuímos, a saber, a Declaração Americana de 1776 e a Declaração Francesa de 1789, documentos que defendem o direito à vida, à liberdade, à igualdade da pessoa humana e à independência dos povos.

O período do Pós $2^{\text {a }}$ Guerra Mundial marcou um tempo em que a discussão dos direitos humanos ganhou maior relevância diante do horror do genocídio, do nazismo e dos totalitarismos, levando a comunidade internacional à criação da Organização das Nações Unidas (ONU) como instituição e referencial para os países.

Assim, em 10 de dezembro de 1948, os países participantes da ONU promulgaram a Declaração Universal dos Direitos Humanos, documento que consagra os direitos civis, políticos, sociais, culturais e econômicos como da ordem dos direitos universais, indivisíveis e interdependentes. Esse mecanismo preconiza um novo paradigma, segundo o qual não deve haver nenhuma violação aos direitos humanos à pessoa humana sob quaisquer condições.

Nesse sentido, os Direitos humanos passaram então a transcender as fronteiras dos Estados e Nações, órgãos e instâncias de defesa, exigindo, assim, a sua atuação protetiva de direitos civis fundamentais de todos (como a vida, a liberdade e a igualdade), direitos politicos (de votar, de ser eleito, de participação política, etc), direitos sociais (educação, moradia, saúde, alimentação, etc), direitos econômicos (a ter renda e condições de sobrevivência) e direitos culturais (lazer, manifestação cultural, acesso à cultura, etc.). 
No Brasil, a luta pelos Direitos Humanos ganhou força social e política no combate ao terrorismo de Estado, ou seja, diante da ditadura instalada em 1964 e aprofundada em 1969 com o Ato Institucional n. 5, chegando à Constituição Federal de 1988, que respirara os ares da Declaração Universal e que ampliou significativamente os direitos sociais e individuais.

No tocante à Educação em Direitos Humanos, mais recentemente o Brasil organizou sua Secretaria Especial dos Direitos Humanos - SEDH com status de Ministério, e constituiu seu Comitê Nacional de Educação em Direitos Humanos composto pela própria SEDH, Ministério da Educação, Ministério da Justiça, Unesco e representantes da Sociedade Civil.

Esse Comitê elaborou em 2003 o Plano Nacional de Educação em Direitos Humanos (PNEDH), que contempla as “concepções, princípios, objetivos, diretrizes e linhas de ação" da educação em direitos humanos no país e se organiza em "cinco grandes eixos de atuação: Educação Básica; Educação Superior; Educação Não Formal; Educação dos Profissionais dos Sistemas de Justiça e Segurança Pública e Educação e Mídia” (Brasil, 2007).

O mote de todo esse processo refere-se a uma tentativa de promover os direitos humanos não apenas a partir da lógica legalista e jurídica, tentando superar a forma fria da lei a partir de fomento de dispositivos educacionais que engendrassem uma cultura de direitos humanos no país.

\section{MAL-ESTAR NO LAÇO SOCIAL E NA EDUCAÇÃO}

A temática da educação, formal ou não formal, nos conduz à questão do animal humano e do mal-estar envolvido em seu processo civilizatório/cultural: somente há humano enquanto ser cultural, civilizado e simbólico, capaz do uso dos processos racionais e subjetivacionais. 
O mal-estar não acaba nesse processo de humanização, mas remete a outro articulado, a saber, a sua relação com a alteridade, de modo que essa constituição se dá vinculada a esse Outro, ${ }^{1}$ sempre anterior ou imediato das relações, do qual emerge angústias, conflitos, agressividade e violência. É preciso forte mecanismo para constituir esse humano em ser social.

Relacionado a esse "mal-estar", temos adotado para o contexto atual a noção de Pós-Modernidade para denominar esse nosso ethos contemporâneo, a partir de autores que o caracterizam como "sociedade pós-tradicional” e "modernidade tardia” (Giddens, 1995), "modernização reflexiva” (Beck, 1995) e “modernidade líquida” (Bauman, 2001).

Mesmo que tal terminologia não seja definitiva e contestada por outros pensadores, a Pós-Modernidade tem sido caracterizada por um tempo marcado por elementos como a fragmentação, a complexidade, a imprevisibilidade, o consumismo, o tecnologismo.

Em contraposição à Idade Antiga, Média e Moderna, a Pós-Modernidade tem sido marcada ainda pela ausência de uma lei homogênea, de referências ordenadoras de sentido e sem um telos (grego, senso de futuro) orientador do sujeito.

Mais que uma mera localização cronológica e um conceito, a pós-modernidade também vem se constituindo como outro ethos, com seus respectivos valores e seus modos de subjetivação.

Se o advento da Modernidade possibilitou diversos pluralismos e sociedades autônomas de sentido, produziu novos sistemas de valores e interpretação “descanonizados”, como também crises de sentido no

${ }^{1}$ Outro, em maiúsculo, refere-se ao radicalmente anterior ao sujeito, podendo se referir aos outros imediatos (pais, avós) como à toda antedescendência genealógica e cultural. 
sujeito, um relativismo generalizado e crises subjetivas e intersubjetivas, agora o indivíduo se encontra emancipado de uma ordenação religiosa (Berger; Luckmann, 2005).

Esse nosso tempo ainda tem seu "espírito" marcado por: um desencantamento diante das utopias políticas, mas também de questionamento da própria ciência positivista; a exacerbação do individualismo e a ausência de projetos humanos coletivos; certo ceticismo e relativismo ético-moral; grande ênfase na heterogeneidade, nos pluralismos e no múltiplo; intensificação dos usos das tecnologias e dos meios de comunicação de massa; enfraquecimento do Estado e dos laços sociais.

Destacamos esses elementos presentes na Pós-Modernidade ao relacionar esse estado de coisas como elementos que vêm provocado um enfraquecimento ou desenlaçamento do laço social, dos mecanismos possibilitadores da manutenção do socius, da civilização.

Por laço social nos baseamos em Freud (1913), ${ }^{2}$ sinalizador de que a ordem social está permanentemente constituída de conflitos, moções agressivas e toda a sorte de emoções antissociais e transgressoras, embora em permanente repressão pela própria civilização. Em outra obra, O mal-estar na civilização, Freud (1996b) fará um complemento a esse argumento, "condenando" de vez a humanidade e seu laço social fragilizado e permeado de conflito entre desejos proibidos versus repressão, a um permanente mal-estar.

\footnotetext{
${ }^{2} \mathrm{Na}$ obra Totem e tabu e outros trabalhos (1996a), Freud discute, dentre outros elementos, a constituição da civilização a partir do Mito da Hordem Primeva, quando estuda os fenômenos tabus e totêmicos, e nesses estudos, o privilegiamento da proibição do incesto como lei universal, a interdição e consequente morte do pai dessa horda como eventos fundantes da humanidade, da cultura e do social. Nesse sentido, de um mito, Freud opera um salto que aponta, pela psicanálise, que denuncia o desejo inconsciente, individual e coletivo, filogenético e ontogenético de violência e morte, denunciando a fragilidade da sustentação do socius diante das tentativas de solidariedade e fraternidade que a civilização insiste buscar. Embora seja uma rica e importante temática, não objetivamos aprofundá-la no escopo deste trabalho.
} 
Segundo Enriquez (1990), a psicanálise freudiana revela que o vínculo ou laço social localiza-se na divisão e conflito do ser pulsional-ser social, no embate entre desejo e interdição, entre a realidade psíquica e a realidade social, entre o inconsciente e o consciente.

Nesse sentido, o contrato social, o socius, será sempre marcado por essa cisão e fragilidade de coesão, e pelo conflito e a violência em estado latente mesmo que se erija a civilização com suas instituições organizadoras.

Ocorre que na Pós-Modernidade, contexto escolhido para a nossa discussão sobre o mal-estar em educar, esse laço social parece estar ainda mais fragilizado, seja pelo enfraquecimento de instituições, valores e práticas ordenadoras de sentido, ou pelo enfraquecimento da Lei e do próprio Estado.

Como elementos-pivôs desse enfraquecimento do laço social, temos refletido sobre o prevalecimento de uma tríade articulada entre individualismo, narcisismo e hedonismo.

Diante do enfraquecimento do socius, ou seja, quando o social se esvazia em seu papel de fornecedor de sentido ou de verdade formular (Guiddens, 1995), o indivíduo passa a sofrer as consequências e reage como pode, sendo, na maioria das vezes, de forma alienada, patológica e sem a devida reflexão de si.

Temos escolhido essa tríade Individualismo-Narcisismo-Hedonismo como elementos na atualidade que cooperam com as profundas relações com esse enfraquecimento do laço social pós-moderno e sua consequente modificação dos processos de subjetivação. $\mathrm{O}$ individualismo-narcisismo-hedonismo se tornam elementos antissociais, fragmentadores de uma possível coesão comunitária e de uma aceitável cultura de direitos humanos. 
Lipovetsky (1983) designa esse nosso tempo como "era do vazio", quando se "substitui" o interdito pela fruição e um clima de liberação do registro da Lei; O filósofo fala de uma "sociedade pós-moralista" caracterizada pelo hedonismo, pelo desinvestimento público, pela perda de sentido das grandes instituições e referências morais, sociais e políticas, e pelo consumo exacerbado.

Dumont (1985) discute o conceito de individualismo como criação ideológica da modernidade e Lasch (1983) caracteriza esse tempo de narcísico a partir da personalidade e da cultura norte-americanas, o que podemos estender ao mundo ocidental.

Operando como uma liga entre individualismo e narcisismo, como elemento-chave no estabelecimento de ordem e valor na atualidade, está o hedonismo facilitado pelo acesso imediatizado pelos avanços da técnica em todos os setores da vida e pelo consumo estimulado e financiado em suaves prestações.

Nesse sentido, felicidade como categoria e horizonte maior, e talvez com certo espectro coletivo e solidário, reduz-se ao prazer imediato e individual, a um hedonismo individualista e narcísico.

Supomos que essa tríade pós-moderna encontraria solo fértil no sistema capitalista ao oferecer meramente bens materiais, mas deixa a desejar quanto aos meios simbólicos de existir, colaborando para um sistema em franca deterioração do laço social e dos processos de subjetivação.

Perseguimos a resposta de Bauman (1998), segundo o qual na pós-modernidade a ordem e a limpeza como categorias que caminham com a civilização seja nas dimensões estética, moral ou ideal, são traduzidas numa nova forma perniciosa de purificação e seleção operadas pelo mercado capitalista que elimina os "consumidores falhos" e aqueles que não podem consumir, considerados novos impuros (Bauman, 1998, p. 20). 
Esses modos de existir mediados pelo capital e pelo consumismo se constituem problema para a sobrevivência real e psíquica, posto que os processos de subjetivação dos sujeitos estão marcados por essa malha invisível que vem enfraquecendo o laço social ao potencializar a agressividade humana latente e intensificar um conflito permanente entre $o$ indivíduo e o social.

Justamente nesse contexto pós-moderno de atomização das relações, do esfacelamento do senso de pertencimento e solidariedade, da real fragilização dos laços sociais, a educação em direitos humanos emerge como utopia desafiadora e necessária para a manutenção da vida e de todo o processo civilizatório. Educar em e para os direitos humanos torna-se uma condição de existência da raça humana.

\section{DESAFIOS À PSICOLOGIA E AO DIREITO: Uma Educação Promotora de Laço Social e de Humanização}

Deparamo-nos, no Brasil, com uma "estrutura violenta e autoritária" de sociedade, com sua história de desigualdade social, econômica e educacional, na qual se fala em democracia, mas as formas de pensamento e mesmo os meios de comunicação não são democráticos.

Utilizando de uma imagem freudiana, os sujeitos e cidadãos não são senhores em sua própria casa, em seu próprio país, excluídos do direito de pensar sua realidade e de se pensar como pessoas e cidadãs.

Existe toda uma maquinaria de controle e intimidação social, de meios de produção de subjetividades submissas e submetidas cultural e ideologicamente à manutenção do status quo. 
Chauí (2006) nos adverte que "as leis sempre foram armas para preservar privilégios e o melhor instrumento para a repressão e a opressão, jamais definindo direitos e deveres concretos e compreensiveis para todos" e prossegue:

A lei não figura o pólo público do poder e da regulação dos conflitos, nunca define direitos e deveres dos cidadãos porque, em nosso país, $a$ tarefa da lei é a conservação de privilégios e o exercício da repressão. Por este motivo, as leis aparecem como inócuas, inúteis ou incompreensiveis, feitas para serem transgredidas e não para serem transformadas - situação violenta que é miticamente transformada num traço positivo, quando a transgressão é elogiada como "o jeitinho brasileiro ${ }^{3}$ (p. 5).

Vimos discutido que a Lei, tão cara à nossa reflexão e práxis, encontra-se na atualidade enfraquecida, senão agonizante, junto com as figuras do pai, o Estado e as instituições ordenadoras, levando ao instituído sujeito fora da lei; o laço social se fragiliza ainda mais ou quem sabe se desenlaça, instituindo laços perversos baseados no mercantilismo, no utilitarismo e na concorrência, conduzindo a uma situação de violência generalizada; os processos de subjetivação se empobrecem e levam a crises pessoais, interpessoais e sociais.

E a Ciência, as Ciências Humanas, em especial o Direito e a Psicologia, diante de tudo isso? Com seus especialistas e seus protocolos, estariam a serviço dessa maquinaria? A Psicologia tem prestado um papel de educação para a liberdade, fraternidade e igualdade, ideais incorporados na Declaração Universal dos Direitos Humanos? Tem se constituído em saber desconfiado e resistente, educativo e desviante diante da homogeneização e da massificação do sistema e cultura capitalistas?

${ }^{3}$ Grifos nossos. 
A filósofa defenderá o que faço coro, ao defender uma educação “ $d a$ e para a cidadania" como "uma ação civilizatória contra a violência social, econômica, política e cultural porque compreende o que são os direitos e age como criadora de direitos (Chauí, 2006, p. 14).

Assim, em educação em direitos humanos, a educação deve ser apreendida como direito inalienável de cada cidadão; exige dos mais diversos campos de saberes e, em particular, da Psicologia e do Direito, o embate caloroso e fecundo com as diversas ciências humanas desde a formação acadêmica até o exercício profissional. Não, entretanto, qualquer formação acadêmica ou exercício profissional, senão aquele que ocorre de forma explícita e comprometidamente com a transformação social. $\mathrm{Ou}$ seja, uma ciência jurídica e psicológica comprometida com a autonomia, com uma forte consciência de direitos humanos e com uma cidadania ativa.

Se Freud (1925/1976) refere a tarefa de educar como exercício da ordem do impossível, tal como a política e o próprio psicanalisar, nos deparamos com a tripla "sina" diante dos direitos humanos: articular em nossa práxis a dimensão educativa, jurídica, política e psicológica a serviço de uma cultura de paz e de promoção da cidadania e da justiça social. Em termos funcionais, temos a difícil, senão utópica, prática de resistir numa ação educativa que não se reduza ao "jurisdiquês" ou ao "psicologuês" repetitivo de artigos e conceitos áridos, mas a um engajamento com a transformação social a partir dos conhecimentos desses saberes.

Se a Constituição Brasileira, promulgada em 1988, apresenta avanços acerca das relações sociais e civis, com aberturas a uma nova configuração de direitos individuais e sociais, sinalizadora da promoção dos direitos humanos, deve ser "explorada" pelos campos da Educação, do Direito e da Psicologia no sentido da acolhida da multiplicidade de configurações grupais e sociais que constitui a diversidade brasileira. 
Essas disciplinas devem fazer um exercício educacional vigilante acerca das rápidas modificações sociais e dos processos de subjetivação de nosso tempo; cabe uma investigação e contribuição desses campos diante das respostas aos novos desafios éticos, sociais e ideológicos de minorias e novos grupos que pleiteiam espaço, vez, voz e dignidade de existir.

Nesse sentido, tanto a Psicologia, como "ciência do singular" e constituintes dos "saberes desnaturalizantes”, quanto a Ciência Jurídica, não devem ater-se às generalizações preconceituosas e mantenedoras da discriminação e da exclusão, mas articuladas ao campo jurídico podem contribuir para uma educação formal e não formal em direitos humanos.

Apenas uma educação interdisciplinar com o horizonte nos direitos humanos pode ser capaz de minimizar a tendência atual do desenlaçamento social que grassa nos indivíduos, grupos e instituições.

Talvez algumas pistas de atuação articulada desses saberes na atualidade seja a formulação de dispositivos sociais e jurídicos de suporte ao sujeito, aos grupos minoritários, às diversas reconfigurações familiares e às entidades/movimentos sociais, de forma a fortalecê-los à luz da democracia republicana.

Esses dispositivos, gerados por esses campos de saber, devem extrapolar a academia e subsidiar as mais diversas políticas públicas de Estado que favoreçam a dignidade humana e os mais diversos direitos individuais e sociais.

Num ethos marcado pelo enfraquecimento dos laços sociais e, portanto, dos laços civilizacionais, caberia ao Direito, à Psicologia e à Educação, o fortalecimento da Lei, elemento ordenador da ordem social, seja na sua elaboração, controle e manutenção, de forma que não houvessem os típicos sujeitos "foras-da-lei", instrumentos antieducativos, perversos e promotores da cultura da violência. Ou seja, fortalecer a Lei significaria para o próprio dispositivo jurídico-legal, por exemplo, a diminuição da 
morosidade e do processualismo ad eternum em que perdem a vítima e favorece o algoz fora-da-lei; para o saber psicológico, por exemplo, o desenvolvimento de conhecimentos que subsidiem políticas públicas e a própria aplicabilidade da lei a sujeitos vulneráveis e/ou delinquentes dela; e à educação, caberia resistir no seu papel de facilitar aos educandos o desenvolvimento de uma leitura/interpretação crítica da realidade, sobretudo relacional e ética. E claro, esses saberes devem, portanto, atuar de forma interdisciplinar, potencializando cada disciplina, de forma que haja um "tripé pró-lei”.

Vimos discutido no campo psi que a Lei tão cara à nossa reflexão e práxis, encontra-se enfraquecida na atualidade, senão agonizante, junto com as figuras do Pai, do Estado e das instituições ordenadoras de sentido (Berger; Luckmann, 2005), levando ao instituído sujeito fora da lei; o laço social se fragiliza ainda mais ou, quem sabe, se desenlaça, instituindo laços perversos baseados no mercantilismo, no utilitarismo e na concorrência desleal, conduzindo a uma situação de violência generalizada; os processos de subjetivação se empobrecem e levam a crises pessoais, interpessoais e sociais.

Assim, a educação deve ser apreendida como direito inalienável de cada cidadão, exigindo dos mais diversos campos de saberes e, em particular, da Psicologia e do Direito, o embate caloroso e fecundo com as diversas ciências humanas desde a formação acadêmica até o exercício profissional.

\section{CASO DA FAMÍLIA ATUAL COMO EXEMPLO DE EDUCAÇÃO EM DIREITOS HUMANOS}

Vimos discutindo a diversidade que abarca o conceito família, com suas variações históricas e culturais, como necessitada de suporte jurídico para sua afirmação na atualidade, sobretudo, com a distinção e privilegia- 
mento dos laços afetivos sobre quaisquer outros dispositivos que tenham surgido no decorrer da dinâmica social e histórica (Lizardo de Assis, 2009; Pereira, 1994). Se o Código Civil brasileiro de 1916 afirma um modelo jurídico de família fundamentado numa concepção de origem romano-cristã, de configuração nuclear e consanguínea e devendo ser sustentada pelo Estado (Brandão; Gonçalves, 2004), esse modelo familiar nuclear, patriarcal e consanguíneo vem dividindo espaço com outras formas de configurações familiares na contemporaneidade, sobretudo após a Constituição Brasileira de 1988.

Esses novos modelos, configurações ou arranjos familiares, quais sejam o modelo da união estável, da comunidade monoparental, da homoparentalidade e outras variações, apontam a plasticidade e o caráter de uma família plural, de uma família-devir, em que o afeto, a estabilidade/ temporalidade, a ostensibilidade, a publicidade (Lôbo, 2002) e os papéis simbólicos da parentalidade emergem como determinantes.

Se existe, no entanto, um mal-estar no que chamamos de "desnaturalização" do conceito tradicional de família diante de novos modelos e arranjos familiares, nos deparamos com uma problemática anterior e talvez relacionada, a saber, certo desenlaçamento social que abarca quaisquer desses modelos familiares.

Estamos cientes do cuidado em estabelecer relações causais entre mudanças sociais da pós-modernidade, os processos de subjetivação e os laços sociais, quando as novas formas de subjetividade ou os processos de subjetivação ocorreriam por escolhas pessoais em contraposição ao poder familiar e da tradição.

Não se descarta, no entanto, que essas mudanças subjetivas acompanhariam as mudanças sociais e econômicas, nem tampouco que essas mudanças nas formas de vida/subjetivação venham ocorrendo de forma tão rápida que não houvera tempo para sua preparação ou assimilação. 
Não podemos desconsiderar a existência de uma crise de valores e referenciais, levando a um estado de confusão no campo das valorações e nos modos de vida, sejam pessoais, interpessoais, familiares e sociais.

Destacamos uma crescente substituição de valores coletivos e sociais (aqueles que se relacionam com a responsabilização pelo outro, por exemplo) por outros meramente individuais, noções como amor e companheirismo substituídos pela mera relação de troca nos vínculos sociais e interpessoais que se tornam vazios de conteúdos subjetivos e se reduzem a jogos de interesses e benefícios.

A substituição e a mudança de valores seriam decorrentes ou acompanhadas do enfraquecimento de instituições sociais como o Estado, a religião e a lei, como que criando para o sujeito pós-moderno um vácuo de sistema orientador (daí o predomínio do consumismo e mercantilismo que atribuímos à lógica/sistema capitalista).

Nesse sentido, defendemos que seja útil estabelecer relações entre a pós-modernidade, a modificação no laço social e os diversos tipos de sofrimentos psíquicos e sociais, individuais e familiares.

E a família, seja qual for sua configuração, estaria marcada por esses impactos "psicossociais”, quais sejam, a ênfase em conquistas/prazeres individuais, a indisposição ou imaturidade para o desafio das relações, o predomínio de relações egocentradas e infantilizadas e a inexistência de projetos comuns.

Diante desse estado de coisas, os públicos que sofrem maior impacto e se tornam as maiores vítimas têm sido as crianças e adolescentes, posto que a família encontra-se marcada pela fragilidade ou inexistência de vínculos saudáveis de pertencimento e amor, e pela falta de disposição ou condição psíquica e emocional para se constituir num locus e modo de relacionar saudável que não permeado pela violência. 
Nesse cenário social maior e, em especial, de instituição plural de família, quando os processos de subjetivação se tornam cada vez mais empobrecidos e se cronificam a des-responsabilização e a incapacidade de envolvimento com/pelo outro, e no qual as instituições ordenadoras de sentido se enfraquecem, defendemos a necessidade de indagar sobre o papel e contribuição de saberes como a Psicologia e o Direito.

\section{CONSIDERAÇÕES FINAIS}

A promoção dos direitos humanos continua um desafio na atualidade, posto que, a despeito de tamanha evolução científica e tecnológica, ainda temos sérias dificuldades em reconhecer o valor da alteridade e o outro como sujeito de direito e dignidade.

Assim, criamos sofisticados equipamentos de comunicação, mas não aperfeiçoamos nossa capacidade de diálogo; avançamos nas descobertas sobre genomas e sinapses cerebrais, mas nos tornamos a cada dia, mais insensíveis às diferenças que constituem a humanidade.

Se não temos em nosso contexto latino-americano, guerras de outrora e em sentido tradicional, vivenciamos uma situação belicosa, de conflitos e de violências de toda sorte, nos bairros e cidades, entre os mais diversos grupos, o que parece minar as possibilidades de laços de solidariedade.

Parece-nos que afirmar ideais humanistas de liberdade e igualdade dispensa práticas e valores de fraternidade, e que nosso socius vive um mal-estar permanente de instabilidade e insegurança.

Os direitos humanos como horizonte diante desse estado de coisas parecem impraticáveis, no entanto devem ser perseguidos como uma utopia, não apenas na sua vertente de correção das violações, mas, sobretudo na promoção de educação em e com direitos humanos. 
Nesse sentido, em março de 1990 em Jomtien, Tailândia, foi realizada pela ONU a Conferência Mundial sobre Educação para Todos Satisfação das Necessidades Básicas de Aprendizagem 40 -, que retoma a Declaração Universal dos Direitos Humanos bem como sua afirmativa da educação como direito de todos. Essa Conferência ${ }^{4}$ parte da reflexão de que a educação básica é essencial para o "progresso pessoal e social”, mas que ainda é uma "educação que hoje é ministrada e apresenta graves deficiências”.

Nessa perspectiva, a Conferência de Jomtien ora critica o sistema escolar e busca seu aperfeiçoamento, ora estabelece a escola como padrão de uma educação praticada nesses projetos sociais, mas nesse tensionamento de "modelos" provoca o pensar sobre uma educação que extrapole apenas um dos espaços.

Sobre a deficiência da educação brasileira (particularmente da instituição escolar pública), não precisamos tecer tantos argumentos, pois as pesquisas e críticas são abundantes, como também os apontamentos e intervenções. A própria Unesco, diante dois impactos da contemporaneidade sobre as relações nacionais, grupais e interpessoais, propõe o desafio de se promover a Cultura de $\mathrm{Paz}$, tendo como seu marco referencial o Manifesto 2000 por uma Cultura de Paz e Não Violência. Nesse sentido, seguindo o "espírito" de Jomtien, suas diretrizes devem ser adotadas numa perspectiva de que o problema da ineficácia da educação deve ser pensado a partir de uma perspectiva sistêmica, que envolva aspectos político-institucionais, filosóficos, pedagógicos, metodológicos e sociais, sem a tradição da culpabilidade do aluno ou do educador. Aqui, também, deve se articular os "três poderes" educacionais da cultura mencionados supra.

${ }^{4}$ Declaração de Jomtien. Disponível em: <http://unesdoc.unesco.org/images/ 0008/000862/086291por.pdf $>$. Acesso em: 30 jun. 2013. 
A Declaração tem o mérito de problematizar a educação básica como responsabilidade não apenas dos governos e dos espaços formais escolares, mas também da sociedade civil organizada, entidades e Organizações Não Governamentais - ONGs - que podem oferecer espaços educativos. Em especial reforçamos a necessidade de uma maior interdisciplinaridade entre Direito, Psicologia e Educação, do espaço acadêmico e sociedade civil, para uma atuação na ótica da educação em direitos humanos e da promoção de uma cultura de paz.

\section{REFERÊNCIAS}

BAUMAN, Z. Modernidade líquida. Rio de Janeiro: Jorge Zahar Editor, 2001. BAUMAN, Z. O mal-estar da pós modernidade. Rio de Janeiro: Jorge Zahar, 1998.

BECK, U. A reinvenção da política: rumo a uma teoria da modernização reflexiva. In: Modernização reflexiva: política, tradição e estética na ordem social moderna. São Paulo: Editora da Universidade Estadual Paulista, 1995.

BERGER, P. L.; LUCKMANN, T. Modernidade, pluralismo e crise de sentido - a orientação do homem moderno. Petrópolis, RJ: Vozes, 2005.

BRANDÃO, E. P.; GONÇALVES, H. S. Psicologia jurídica no Brasil. Rio de Janeiro: Editora Nau, 2004.

BRASIL. Comitê Nacional de Educação em Direitos Humanos. Plano Nacional de Educação em Direitos Humanos. Brasília: Secretaria Especial dos Direitos Humanos, 2007.

CHAUÍ, M. Direitos humanos e educação. Congresso sobre Direitos Humanos. Brasília, 2006. Disponível em: <http://www.dhnet.org.br/dados/textos/a_pdf/ chaui_dh_educacao.pdf $>$. Acesso em: 27 out. 2012.

DUMONT, L. O individualismo: uma perspectiva antropológica da ideologia moderna. Rio de Janeiro: Rocco, 1985.

ENRIQUEZ, E. Da horda ao Estado. Psicanálise do vínculo social. Rio de Janeiro: Jorge Zahar, 1990. 
FREUD, S. (1913). Totem e tabu e outros trabalhos. Edição Standard Brasileira das Obras psicológicas completas de Sigmund Freud, vol. XIII. Rio de Janeiro: Imago Editora, 1996a.

FREUD, S. (1929). O mal-estar na civilização. Edição Standard Brasileira das Obras Psicológicas Completas de Sigmund Freud, vol. 21. Rio de Janeiro: Imago. Originalmente publicado em 1996b.

FREUD, S. (1937). Análise terminável e interminável. Edição Standard Brasileira das Obras Psicológicas Completas, vol XXIII. Tradução D. Marcondes e outros. Rio de Janeiro: Imago, 1988.

GIDDENS. A. A vida em uma sociedade pós-industrial. In: Modernização reflexiva: política, tradição e estética na ordem social moderna. São Paulo: Editora da Universidade Estadual Paulista, 1995.

LASCH, C. A cultura do narcisismo: a vida americana numa era de esperanças em declínio. Rio de Janeiro: Imago, 1983.

LIPOVETSKY, G. A era do vazio: ensaio sobre o individualismo contemporâneo. Lisboa: Relógio D’Água, 1983.

LIZARDO DE ASSIS, C. Famíliafeto: a família como laço afetivo no Direito e na Psicologia. In: CONGRESSO NACIONAL DE PSICANÁLISE, DIREITO E LITERATURA, 1., 2009, Nova Lima. Anais... Nova Lima-MG: Faculdade Milton Campos, 2009. p. 286-300.

LÔBO, P. L. N. Entidades familiares constitucionalizadas: para além do numerus clausus. Jus Navigandi, Teresina, a. 6, n. 53, jan. 2002. Disponível em: $<$ http://jus2.uol.com.br/doutrina/texto.asp?id=2552>. Acesso em: 27 jul. 2013. PEREIRA, R. C. Concubinato e união estável. Belo Horizonte: Del Rey, 1994. UNESCO. Declaração de Jomtien. Disponível em: <http://unesdoc.unesco. org/images/0008/000862/086291por.pdf>. Acesso em: 30 set. 2012.

Recebido em: 13/3/2013

Revisado em: 4/10/2013

Aceito em: 11/10/2013 